\title{
ATITUDES E CRENÇAS LINGUÍSTICAS EM UM CENÁRIO MULTILINGUE
}

\section{ATTITUDES AND BELIEFS IN A MULTILINGUAL SCENERY}

\author{
Roberto Gomes Camacho \\ Universidade Estadual Paulista “Júlio de Mesquita Filho”, São José do Rio Preto, São Paulo, \\ Brasil
}

Ana Helena Rufo Fiamengui

Instituto Federal de Educação, Ciência e Tecnologia, São Paulo, São Paulo, Brasil

Resumo: Numa situação multilíngue, como a da fronteira Ponta Porã/Juan Pedro Caballero, o processo de alfabetização e todo o ensino subsequente de língua entram seriamente em conflito com o grau de letramento possível de que dispõem os alunos paraguaios, um caso exemplar de cumprimento de um aspecto teórico levantado por Street (2007): o caráter dominante de uma cultura, que é, nesse âmbito, o letramento em português ou em espanhol de falantes do guarani como L1. A hipótese que pretendemos desenvolver aqui é, portanto, a de que, como o processo de letramento inclui atitudes e crenças compartilhadas pelos alunos, essa relação inclusiva seria um mecanismo imprescindível ao desenvolvimento do processo formal de alfabetização e de práticas sociais de escrita e leitura, especialmente quando destituídos do preconceito advindo da imposição de letramento dominante.

Palavras-chave: Multilinguismo; Letramento; Atitude; Crença

\begin{abstract}
In a multilingual situation, such as the border Ponta Porã/Pedro Juan Caballero, the schooling process and all subsequent linguistic teaching seriously enter into conflict with the degree of literacy as possibly available to Paraguayans students, an exemplary case of fulfillment of a theoretical aspect raised by Street (2007): the dominant character of a culture, which is, in this context, the Portuguese/Spanish-based literacy of Guaraní speakers as L1. The hypothesis that we develop here is, therefore, that, as the process of literacy includes attitudes and beliefs shared by students, this inclusive relationship would be a mechanism essential to the development of the formal schooling and social practices of writing and reading, especially when devoid of prejudice arising from the imposition of dominant literacy.
\end{abstract} Keywords: Multilingualism; Literacy; Attitudes; Beliefs 


\section{ABRINDO A CORTINA E APRESENTANDO O CENÁRIO}

A cidade de Ponta Porã, localizada no sul de Mato Grosso do Sul, faz fronteira com Pedro Juan Caballero, capital do departamento de Amambay do Paraguai, situação que provoca um fluxo contínuo de pessoas e mercadorias, bem como de bens e valores simbólicos, que incluem o intercâmbio linguístico e cultural entre os países envolvidos. De acordo com o SEBRAE (2010), as cidades de Ponta Porã e Pedro Juan Caballero constituem uma das maiores conurbações da América Latina. A separação dos limites fronteiriços se dá apenas por uma larga via, a Avenida Internacional, ao longo da qual se concentram as atividades comerciais, um caso típico de fronteira seca, que facilita o intercâmbio de alunos, especialmente o de paraguaios a escolas brasileiras.

O fato de o Brasil ter o português como língua oficial, e o Paraguai, desde 1992, o espanhol e o guarani, conduz à existência de distintas realidades convivendo em uma mesma instituição escolar, com o agravante de terem certas escolas $90 \%$ de seus alunos provindos do Paraguai, tendo o guarani como língua veicular. Mesmo nas escolas em que a maioria dos alunos dispõe do português como língua materna, elas guardam também muita familiaridade com as duas línguas paraguaias; ainda assim, não passam despercebidas certas demonstrações explícitas de preconceito, dirigidas especificamente ao guarani, que, a despeito de seu estatuto de língua oficial, fica confinado ao uso dos indivíduos de classes média e baixa e até certa medida, da zona rural do Paraguai.

Em função desse cenário desalentador, este texto se debruça sobre um aspecto científica e socioculturalmente relevante da situação de uma zona de fronteira, que é o da diversidade linguística e seus desdobramentos, especialmente em relação aos processos de alfabetização e letramento.

Nessas situações, o processo de alfabetização e todo o ensino subsequente de língua entram seriamente em conflito com o grau de letramento possível de que dispõem os alunos, especialmente os paraguaios, um caso exemplar de cumprimento de um aspecto teórico levantado por Street (2007): o caráter dominante de uma cultura, que é, nesse âmbito, o letramento em português ou em espanhol de falantes do guarani como L1, disfarça-se por trás de discursos públicos de neutralidade nos quais se apresenta o "letramento dominante", seja em espanhol seja em português, como o único aceitável.

Street (2007) sugere a adoção do conceito de letramento dominante em consonância com o modo como a sociolinguística vê a relação entre a norma padrão e as variedades estigmatizadas, ao reconhecer que a variedade que a comunidade identifica como padrão não passa de apenas uma entre tantas, embora seja tratada como língua dominante.

A expressão língua dominante, por um lado, deixa explícito que alcançar o status que o significado sugere tem origem nas lutas por poder e dominação e não necessariamente num "processo natural de emergência do 'melhor' como padrão" (GRILLO, 1989 apud STREET, 2007, p. 472). A adoção do conceito de letramento dominante, por outro lado, tem a função de salientar "a extensão com que o letramento que é tratado como padrão é igualmente é apenas uma variedade entre muitas e que a questão de como ele se tornou o padrão é igualmente uma questão de poder" (STREET, 2007, p. 472).

A hipótese que pretendemos desenvolver aqui é, portanto, a de que valores sociais, como atitudes e crenças linguísticas, compartilhadas por alunos em situação de aprendizagem, constituem um mecanismo imprescindível ao desenvolvimento qualificado do processo formal de alfabetização e de práticas sociais de escrita e leitura, especialmente quando destituídos do preconceito advindo do letramento dominante.

Entendemos que reações subjetivas fazem parte, na realidade, das práticas de letramento, no sentido que lhes imprime Street (2007). Segundo esse autor, existem modos diferentes de representar usos e significados de ler e escrever em diferentes contextos sociais 
e, nesse caso, é o testemunho de sociedades e épocas diferentes que demonstra ser enganoso pensar em um tipo único e compacto de letramento.

Como Street (2007), preferimos assentar nosso trabalho aqui na base no que ele denomina modelo ideológico de letramento,

o qual reconhece uma multiplicidade de letramentos; que o significado e os usos das práticas de letramento estão relacionados com contextos culturais específicos; e que essas práticas estão sempre associadas com relações de poder e ideologia: não são simplesmente tecnologias neutras (Street, 1985, 1993) (STREET, 2007, p. 466).

Para desenvolver essa hipótese, este texto retoma algumas conclusões mais pontuais, mas também mais relevantes, da pesquisa desenvolvida por Fiamengui (2017), que trata de descrever, da maneira mais rigorosa e consistente possível, atitudes e crenças dos alunos em relação às línguas da fronteira. Por razões óbvias de espaço, este texto se restringirá à análise de aspectos qualitativos da análise de atitudes e crenças, procurando estabelecer uma correlação entre o preconceito linguístico mencionado por professores e pais de alunos e as reações subjetivas dos alunos que estudam em escolas brasileiras e paraguaias.

\section{PONDO OS PINGOS NOS IS: CONCEITOS DE ALFABETIZAÇÃO E LETRAMENTO}

A discussão iniciada acima deixou suficientemente claro que, para nós, letramento e alfabetização são processos interligados, mas diferentes. Num texto em que discute o conceito de letramento de uma perspectiva histórica e a-histórica, Tfouni (1994) desfaz qualquer confusão entre alfabetização e letramento postulando uma concepção sócio histórica, cujo critério central se abriga na concepção discursiva de autoria.

Para a autora, a dimensão histórica do processo de letramento se identifica com o lugar do sujeito no interdiscurso "que lhe possibilite organizar o intra-discurso (oral ou escrito) que está produzindo, de forma a produzir um texto" (TFOUNI, 1994, p. 61). Ademais, a coincidência entre as posições discursivas de sujeito e de autor tem mão dupla, ou seja, do oral para o escrito e do escrito para o oral. Desse modo, o conceito histórico de letramento centralizaria esse processo de mão dupla que, conforme enfatiza a autora, "não tem uma relação necessária com a alfabetização" (TFOUNI, 1994, p. 61).

A autora chega a radicalizar a diferença entre letramento e escolaridade mediante a análise de dois textos, um escrito por uma universitária no contexto escolar e outro, a gravação da fala de uma pessoa não alfabetizada. O texto escrito é uma projeção da imagem que a autora tem da escrita: estilo formal, léxico distante do registro quotidiano; no entanto, a intenção de ser formal ativa no texto da universitária algo próximo de uma paródia do registro formal, em que abundam palavras de um eruditismo desgastado em períodos redundantes, além de desvios das convenções ortográficas. Esse texto indicia "um descompasso entre a necessidade de controle de um estilo escrito formalizado e a falta de estrutura para mantê-lo" (TFOUNI, 1994, p. 55).

Já da narrativa oralmente produzida, Tfouni (1994) faz menção especial a um ponto crucial de produção de diferentes efeitos de sentido, em que se destaca certo grau de cumplicidade entre autora e audiência, mediante o uso de perguntas retóricas e de efeito suspensivo do fio narrativo. É esse mecanismo argumentativo que garante ao texto falado um grau de letramento que o torna, nesse aspecto, até superior ao do texto escrito.

Com base na análise desses recursos, Tfouni considera que a explicação para essa divergência deve ser buscada em uma concepção sócio-histórica de letramento cujo critério crucial esteja centrado na concepção discursiva de autoria. Nesse caso, a função autor não é uma prerrogativa circunscrita apenas a quem é capaz de ler e escrever, mas está ligada ao 
discurso letrado: por ser social e historicamente constituído, o discurso letrado pode estar acessível também àqueles que não dominam o código escrito. É justamente nesses termos que a coincidência de posições discursivas de sujeito e de autor tem mão dupla, ou seja, vai do oral para o escrito e do escrito para o oral, sem haver uma relação necessária entre escolarização formal e letramento (TFOUNI, 1994).

Soares (2004) também destaca a diferença fundamental entre letramento e alfabetização com base no grau da ênfase que se põe nas relações entre as práticas sociais de leitura e de escrita e a aprendizagem do sistema de escrita, ou seja, entre o conceito de letramento e o conceito de alfabetização. Num texto anterior a esse, a mesma autora reafirma que o problema do ensino "não é apenas ensinar a ler e a escrever, mas é também e, sobretudo, levar os indivíduos - crianças e adultos - a fazer uso da leitura e da escrita, envolver-se em práticas sociais de leitura e de escrita" (SOARES, 1998, p. 18).

Soares (2004) entende que essa preocupação com práticas sociais de leitura e de escrita tenha surgido inicialmente nos países do Primeiro Mundo como um problema relevante a ser encarado diante da constatação de que, embora alfabetizada, a população em geral não era capaz de dominar "as habilidades de leitura e de escrita necessárias para uma participação efetiva e competente nas práticas sociais e profissionais que envolvem a língua escrita" (SOARES, 2004, p. 6). O problema não se localizaria no conceito de illiteracy, entendido como não saber ler e escrever, mas no de literacy, entendido como não domínio de competências da leitura e da escrita (SOARES, 2004).

Outro aspecto crucial para os objetivos deste trabalho é o da relação entre letramento e identidade. Street (2006) considera que as práticas de letramento são constitutivas da identidade e da pessoalidade (personhood): quaisquer formas de leitura e de escrita que se aprendam e se usem estão associadas a determinadas identidades e expectativas sociais acerca de modelos de comportamento e papéis a desempenhar. Entendemos que na noção de identidade de Street (2007) parece operar o que se denomina, em sociolinguística, por "prestígio encoberto"1, um valor que pode emergir da análise de atitudes e crenças.

Nas escolas da fronteira Ponta Porã/Juan Pedro Caballero, é possível que as práticas de letramento envolvidas conduzam a diferentes identidades na dependência do grau de prestígio que os alunos envolvidos atribuem à L1 e à L2; a resistência ao letramento em L2, português ou espanhol, para falantes do guarani, pode estar ligada a valores de prestígio encoberto e afeto pessoal decorrentes de sua relação com a língua materna ${ }^{2}$; por outro lado, o abandono do guarani em favor de uma segunda língua pode estar em relação com o letramento dominante, considerado por eles como de maior grau de prestígio e de status.

\section{O MULTILINGUISMO DA FRONTEIRA E A QUESTÃO DO ENSINO}

Considerando especificamente a situação paraguaia, Gaona Velázques (2013) argumenta que, além de reconhecer o Paraguai como um país multicultural e bilíngue, tendo o espanhol e o guarani como línguas oficiais, a Constituição Nacional de 1992 dispõe sobre a obrigatoriedade do uso da língua materna no início do processo escolar, não só para leitura e escrita, mas para todas as áreas do conhecimento.

\footnotetext{
${ }^{1}$ Ao questionar por que as pessoas nem sempre se exprimem como obviamente acreditam que deveriam exprimir-se, Labov (2008 [1972]) responde postulando a existência de um conjunto oposto de normas, que atribui valores positivos à variedade mais informal e não necessariamente à variedade padrão. Esse valor tácito ficou conhecido como "prestígio encoberto" (covert prestige), o termo que Trudgill (1972) lhe atribuiu ao fornecer também a primeira evidência objetiva para o fenômeno com base em diferenças de comportamento de gênero.

${ }^{2} \mathrm{O}$ conceito de língua materna, tomado aqui como equivalente de primeira língua é a que se aprende primeiro em casa e que normalmente é a língua da comunidade. Essa língua implica a existência de um fator identitário e é a partir dela que se adquirem o conhecimento de mundo e os valores pessoais e sociais (SPINASSÉ, 2006).
} 
Gaona Velázquez (2013) destaca a condição bilíngue incomum do Paraguai por ser o único país em que uma língua indígena é falada até pela maioria não indígena de seus habitantes. Ainda que as duas línguas coexistam em grau maior ou menor em todas as esferas, a autora reconhece que predomina o uso do espanhol nos meios de comunicação de massa, em áreas públicas, políticas, jurídicas e institucionais, enquanto o uso do guarani, que se circunscreve ao âmbito oral, próximo e afetivo, especialmente no seio familiar, é daí levado para contextos profissionais, espaços recreativos e informais.

Entende a autora que esse cenário poderia ser identificado como o de uma situação de diglossia ${ }^{3}$. Ela defende, porém, não ser esse o caso, visto que o uso das duas línguas em espaços próprios gera uma relação de complementaridade, havendo, inclusive, quem alterne o tempo todo entre uma e outra.

É, todavia, bem ao contrário o que pensa Fishman (1967), autor que postula ser a situação do Paraguai um exemplo tradicional de sociedade bilíngue e diglóssica, em que as populações rurais primitivas adicionaram o espanhol a seus repertórios para falar e escrever sobre educação, religião, alta cultura e atos governamentais, ou seja, esferas de status mais proeminente, embora a maioria dos moradores preserve o guarani para questões de intimidade e solidariedade ao grupo primário mesmo em meio urbano.

Outros pesquisadores, como Jiménez (2011) e Zarratea (2012) também defendem a ideia de que o bilinguismo paraguaio realmente constitui uma situação diglóssica, sustentados no fato de as línguas não gozarem do mesmo status ou prestígio social. Segundo Jiménez,

la situación linguística del Paraguay, como hecho social y político, es diglósica. Para todos los efectos el monolíngue guaraní es considerado inferior y sufre pena por este hecho, desde la falta de oportunidades que le oferece la escuela hasta la merma de opciones de trabajo. (JIMÉNEZ, 2011, p. 59)

Para Zarratea (2012), o bilinguismo paraguaio é diatópico, por constituir um processo compartilhado em todo o território nacional; diastrástico por permear todos os estratos sociais; diacrônico por ser um resultante de fatos históricos e, por fim, diglóssico, por ter cada língua áreas preferenciais de uso. Reafirma o autor a dificuldade de encontrar bilíngues coordenados, ou perfeitos na denominação de MacNamara (2010), ou seja, indivíduos que compreendam, falem, leiam e escrevam com a mesma fluência as duas línguas, talvez porque nunca tenha sido realmente aplicado o processo de alfabetização ao guarani, a primeira língua da maioria.

O que acentuou a tensão entre os dois idiomas, segundo Gaona Velázquez (2013), foi um drástico processo de urbanização. Nos últimos trinta anos, o Paraguai, um país historicamente rural, passou por transformações econômicas e sociais aceleradas, que produziram migração de grandes levas do campo para a cidade.

Ao chegar à capital e a sua periferia, os migrantes tendem a tomar consciência da importância do espanhol como instrumento de ligação com o mundo externo e também como meio de obtenção de emprego. É comum que, nesse contexto, os adultos se comuniquem em guarani, mas usem o espanhol para falar com os filhos, demonstrando a importância que atribuem à aprendizagem do espanhol.

A respeito das atitudes em relação ao guarani e ao espanhol, Gaona Velázquez (2013) argumenta que, como os pais pensam que as crianças falantes de guarani serão socioculturalmente estigmatizadas, eles as enviam à escola para aprender espanhol. Essa

\footnotetext{
3 Para Fishman (1968), em uma situação de diglossia, a sociedade reconhece duas ou mais línguas como próprias, embora cada uma delas tenha domínios funcionalmente exclusivos. De acordo com esse autor, tal noção foi inicialmente proposta por Ferguson (1959) e ampliada por Gumperz (1968) para abranger sociedades que empregam dialetos, registros ou variedades funcionalmente diferenciados de qualquer tipo.
} 
atitude, que reflete a crença de que é preciso ser falante dessa língua para ser socialmente reconhecido e ter acesso ao processo de mobilidade social ascendente, se dá no claro contexto de letramento ideológico, em que falantes do guarani acabam por rechaçar sua própria língua nativa.

Nesse âmbito do ensino, a Reforma Educacional de 1992, que reconstrói a condição marginal do guarani para inseri-lo como matéria de estudo e língua de instrução, previa que os anos iniciais dessem maior ênfase à língua materna, sendo a segunda língua incorporada aos poucos. Em 1994, o Ministério da Educação implantou o programa bilíngue, sem, considerar no entanto, a realidade sociolinguística das localidades envolvidas, situação que gerou confusão e falta de apoio das famílias à continuidade da proposta.

2004 testemunhou o início de um projeto piloto em treze escolas de uma mesma região, que permitiu ampliar o modelo de educação, tornando-o flexível aos diferentes grupos sociais. No entanto, pesquisas de campo mostraram que até 2013 essa proposta ainda não se havia viabilizado, pondo-se, em seu lugar, a submissão dos alunos a um processo de alfabetização em espanhol, como se fosse a primeira língua de todos, uma política de ensino que pode conduzir ao rechaço da própria língua e a uma crise comunicativa (GAONA VELÁZQUEZ, 2013).

Essa situação sinaliza claramente que a possibilidade de modos diversos de representação dos usos e os significados de ler e escrever em diferentes contextos sociais entra em contradição com a visão de um letramento único e autônomo, em plena conformidade ao que Street (2007) denomina modelo ideológico de letramento.

Até 1994, era objetivo das autoridades educacionais atingir uma situação de bilinguismo universal, reservando-se às duas línguas um espaço próprio de expressão de realidades socioculturais diferentes (GYNAN, 2007). Essa concepção, no entanto, deixa o guarani, logo de saída, em uma desvantagem funcional, especialmente em termos de letramento, já que o uso do espanhol é muito mais frequente em práticas sociais de leitura e de escrita, enquanto a funcionalidade do guarani está mais circunscrita à oralidade.

Se a situação bilíngue paraguaia não se constitui, dentro de seus limites, um caso totalmente pacífico, o cenário tende a complicar-se ainda mais por se somar, à divergência de status, o problema adicional da influência do português, que permeia, em maior ou menor grau, a vida de todos os habitantes fronteiriços.

Enfocando especialmente a situação linguística de escolas da fronteira Ponta Porã/Juan Pedro Caballero, Silva e Tristoni (2010) afirmam que o aluno que domina apenas a(s) língua(s) paraguaia(s) e é matriculado em uma escola brasileira se vê envolvido em conflitos culturais, étnicos, linguísticos e identitários por ser sua língua vista como errada ou inferior na situação escolar de imposição da variedade padrão do português. Reforça esse problema a atuação errática de coordenadores pedagógicos, dirigida a coibir "sotaques" do falar paraguaio, situação que gera um sentimento de vergonha e insegurança nos alunos. Um caso típico de letramento dominante.

\section{ATITUDES E CRENÇAS E A CONSTRUÇÃO DE IDENTIDADE}

O estudo de atitudes e crenças linguísticas remonta à década de 60, quando Lambert et al. (1960) investigaram a avaliação de canadenses falantes de francês e de inglês em relação à sua própria língua, experimento que passou a ser conhecido como matched guise technique, ou "técnica dos falsos pares". A sonoridade de uma língua ouvida numa gravação e traços de sua codificação fonológica e morfossintática despertam percepções das características estereotipadas em relação ao grupo que a fala, que se reflete em reações subjetivas generalizadas. Com base nisso, Lambert et al. (1960) propuseram-se determinar os 
significados que a língua falada tem para os ouvintes a partir da análise de suas reações subjetivas à audição do inglês e do francês na comunidade de Montreal, comunidade cuja história se centra amplamente na separação entre essas duas línguas, e cuja distinção é socialmente significativa para seus residentes.

Os resultados mostram que os juízes, falantes de inglês e francês, avaliaram mais positivamente o correspondente inglês, o que coincide com a possibilidade em maior grau de encontrar falantes do inglês em posições de maior grau de status social e poder econômico na comunidade de Montreal.

Labov (2008 [1972]) também analisou as atitudes de informantes em relação a variáveis linguísticas específicas, como o estudo que realizou da fala de Nova Iorque, quando descobriu que a presença ou ausência de $/ \mathrm{r} /$ em posição pós-vocálica estaria relacionada a atitudes de estigma e prestígio. Os resultados mostram que uma característica social relevante é faixa etária, já que as diferenças apontam para uma reação positiva à inserção de $/ \mathrm{r} / \mathrm{na}$ avaliação dos mais jovens, enquanto os indivíduos com mais de 40 anos ainda se mostram mais receptivos à preservação do padrão diacronicamente mais antigo de ausência de $/ \mathrm{r} /$.

É possível estender esse princípio variacionista à situação em que, em vez de um espaço de coexistência de diferentes variedades, o espaço possível seja o de coexistência de diferentes línguas em uma situação multilíngue, como o contexto da fronteira, especialmente em virtude de o espanhol desfrutar de um grau de prestígio social ainda não atingido pelo guarani.

Mesmo após a ascensão política ao status de língua oficial, o uso do guarani foi proibido por muito tempo nas escolas, especialmente as de ensino privado, certamente em razão do estigma de ser o guarani uma língua indígena e, sobretudo, predominantemente falada por pessoas de classe baixa da zona rural. Nesse cenário, está mais do que claro que o conceito de língua dominante implica o de letramento dominante, tipo de clube no cenário multilíngue da fronteira, em que o guarani não é apenas não convidado, mas constitui também persona non grata.

Os procedimentos metodológicos envolveram basicamente as seguintes etapas: gravação dos estímulos para aplicação no teste de atitudes, constituição dos testes de atitudes e de crenças, seleção das escolas onde foram aplicados os testes, aplicação dos testes, tratamento estatísticos dos dados e elaboração de tabelas para visualização dos resultados. Por razões de espaço, reduzimos a análise aos aspectos qualitativos.

A primeira etapa envolveu a procura de falantes trilíngues que se dispusessem a gravar a leitura de uma fábula previamente selecionada. A fábula, encontrada nas versões em português e guarani em um site eletrônico ${ }^{4}$, foi depois traduzida para o espanhol.

Os questionários foram organizados em três partes. A primeira, construída com base principalmente na matched guise technique, que representou uma aferição de atitudes, envolveu o emprego de treze atributos, cada qual com alternativas representando as notas de 1 a 7. A inserção dos seis primeiros atributos, que se assentou no trabalho de Cyranka (2007), teve a função de testar as dimensões de poder (inteligente, competente, rica) e de solidariedade (honesta, simpática, boa pessoa). A responsabilidade pela seleção dos atributos bonita (boa aparência para Lambert et al., 1960), forte e responsável se pautou pela pesquisa de Wölck (1973).

A decisão de inserir sociável foi motivada pelo fato de ter sido detectado na pesquisa etnográfica que nem todos os alunos participam igualmente da vida social da escola, situação que pareceu, muitas vezes, estar relacionada a alguma diferença linguística e/ou cultural. Por fim, os atributos alegre, similar a gracioso de Lambert et al. (1960) e trabalhador, destacaram-se nos questionários aplicados a alunos e docentes na pesquisa etnográfica.

${ }^{4}<\underline{\text { http://guaraniportugues.blogspot.com.br/2009/04/kai-ha-jaguarete-o-macaco-e-onca.html }>\text { Acesso }}$ em: $15 / 01 / 2015$ 
A segunda parte do questionário teve o objetivo de desvelar as crenças dos alunos avaliadores em relação a assertivas muito recorrentes na zona de fronteira. A metodologia aplicada, com base em Barbosa (2009), tratou de inserir 36 assertivas já flagradas no uso da língua da comunidade para compor o questionário de crenças, com as quais os alunos deveriam demonstrar concordância ou discordância (total ou parcial). Para as respostas possíveis, utilizamos a escala Likert (1932), um tipo de escala de resposta psicométrica usada habitualmente em pesquisas de opinião.

Ao responderem a um questionário baseado nessa escala, os participantes especificam seu nível de concordância com uma assertiva (LIKERT, 1932). O objetivo desse teste é fornecer evidências para buscar correlações com dados encontrados no teste de atitudes, mas agora de uma maneira mais direta, com base na reflexão explícita sobre a língua. A organização formal classificou as assertivas elencadas em cinco grupos inspirados em Baker (1992): crenças em relação à língua, crenças em relação a uma variedade linguística, crenças em relação às pessoas que as falam, crenças em relação ao uso das línguas, crenças em relação ao bilinguismo.

A terceira etapa dos procedimentos metodológicos envolveu a seleção das escolas em que seriam aplicados os questionários. A decisão de investigar as reações subjetivas de estudantes de lugares diferentes requereu a seleção de escolas centrais, periféricas e rurais, além de escolas públicas e particulares nos dois países da fronteira, de que resultou um total de 324 participantes de dez instituições de ensino.

Passando, agora, diretamente para a discussão das reações subjetivas, os resultados estatísticos do teste de atitudes, quando considerados todos os participantes, independentemente do lado fronteiriço em que estudam, apontam em geral para um sentimento de estigmatização do guarani e, mutatis mutandis, de atribuição de um grau mais elevado de prestígio ao português, com o espanhol numa posição intermediária. Os procedimentos quantitativos permitiram agrupar os atributos em quatro dimensões: de caráter (trabalhadora, confiável, responsável), de competência (competente, honesta, inteligente), de relacionamento (alegre, simpática, sociável) e de aparência (bonita,forte, rica).

Com relação à dimensão de caráter, os alunos de escolas brasileiras classificam em geral o falante do português como superior aos das outras duas línguas, com o do espanhol recebendo uma nota intermediária e o do guarani, as notas mais baixas. Já os alunos paraguaios tendem a avaliar mais positivamente uma de suas línguas nativas, embora não se possa afirmar a existência de uma direção única para os resultados desse procedimento.

Os atributos da dimensão da competência demonstram, por seu lado, uma tendência mais clara de privilegiar o português independentemente do país em que estudam os respondentes, o que deve estar relacionado ao fato de ser mais provável encontrar brasileiros em posições mais privilegiadas socioeconomicamente e que requeiram níveis mais elevados de estudos.

Com relação à análise dos atributos relacionados à dimensão do relacionamento, que denotam valor emocional em algum grau, as reações subjetivas permitiram verificar uma clara ascensão do guarani em relação à avaliação positiva dos alunos de escolas paraguaias. Ainda que a avaliação do guarani não chegue a ultrapassar a do português, a essa língua indígena se atribui pontuação mais elevada que a do espanhol, o que faz transparecer traços de certo grau de prestígio encoberto. Nas escolas brasileiras, o português recebe nessa dimensão também uma apreciação positiva de grau mais elevado.

Quanto à dimensão da aparência, detectou-se uma tendência dos avaliadores das escolas brasileiras a uma avaliação mais positiva do português, seguida normalmente do espanhol e, só por fim, do guarani. Também os adolescentes de escolas paraguaias demonstram certa preferência pelo português em relação a esses atributos, ainda que o guarani tenha recebido uma avaliação mais positiva que a do espanhol na maior parte dos casos. 
Esses resultados demonstram que é em geral o português que se configura como a língua mais prestigiosa na zona fronteiriça. Em atributos que denotam maior valor emocional, há reações positivas favoráveis ao guarani, considerando que, em alguns casos, atribui-se a essa língua avaliação mais positiva que ao espanhol.

O grau de bilinguismo dos respondentes se mostra relevante na avaliação dos atributos da dimensão da aparência (bonita, forte e rica), na medida em que se entrevê uma relação diretamente proporcional entre aumento progressivo das médias e grau crescente de bilinguismo. Em relação aos outros atributos, os resultados variam conforme varia a língua enfocada. É razoável afirmar que, em virtude do estereótipo negativo, o grau de bilinguismo dos respondentes afeta mais consistentemente também os atributos de outras dimensões aplicados ao guarani.

O teste de crenças, em geral, acompanha a atribuição de prestígio e estigma revelada pelo teste de atitudes. O português e o espanhol são considerados mais bonitos, mais importantes, mais usados e, em escala muito menor, alvos de preconceito. Entretanto, também o guarani é considerado funcional, o que se contrapõe ao resultado do teste de atitudes. Podese atribuir essa divergência entre atitudes e crenças a um comportamento socialmente manifesto de ocultar opiniões explicitamente preconceituosas, um preconceito velado, embora persista fortemente abaixo do nível da reflexão explícita sobre a língua.

Emergem, do teste de crenças, pelo menos três questões que precisam ser analisadas com maior cuidado. A primeira se refere ao comportamento distinto dos respondentes das escolas particulares, principalmente em relação às assertivas envolvendo o guarani, o que pode implicar a existência de alguma correlação com o status socioeconômico, que passa a exercer um papel relevante na expressão das crenças.

A segunda se relaciona à percepção dos alunos de que, embora a importância do espanhol se estenda para além da comunicação no contexto fronteiriço, a variedade ali falada não seria tão prestigiada, sobretudo em razão de mescla com os outros dois idiomas locais.

$\mathrm{O}$ terceiro ponto digno de menção se refere a assertivas renegando o guarani, como "Há muitos alunos que negam saber guarani" e "Há pais que não querem que os filhos aprendam guarani", que geraram concordância da maior parte dos respondentes de quase todas as escolas, não só das brasileiras, como seria de supor. Esse resultado se relaciona à origem e à manutenção do preconceito em relação ao guarani. Reconhece-se preconceito não só nas escolas, mas no interior da própria família, não obstante a importância fundamental dessa língua na zona fronteiriça em foco. A esse respeito, afirma Erickson:

\footnotetext{
Hegemonic practices are not only ramified throughout the general society and in the local community outside the school, they are also alive and well inside the classroom. They permeate and frame the school experience of students who are members of stigmatized social groups (ERICKSON, 1987, p. 352).
}

Por "prática hegemônica", o autor entende ações cotidianas e crenças pré-concebidas em sintonia com o sistema cultural de significados que sistematicamente limitam as chances de grupos estigmatizados. Certamente é possível estender esse argumento às atitudes abertas de prestígio e preconceito que ocorrem dentro de sala de aula, na sociedade como um todo e, de acordo com as respostas dos alunos, também no seio familiar.

De fato, os resultados discutidos comprovam a existência real de modos diversos de representar os usos e os significados de ler e escrever em diferentes contextos sociais contrariamente à noção da aquisição de um letramento único e autônomo, o que vai ao encontro do que Street (2007) denomina modelo ideológico de letramento.

Essa inferência é particularmente verdadeira se levarmos em conta o fato de não apenas ser o guarani a língua mais estigmatizada da zona fronteiriça em foco, mas também se levarmos em conta o fato de que, embora tendam as escolas públicas paraguaias de periferia e 
da zona rural a manifestar uma ligação mais forte com o guarani, seria de esperar uma reação de estigmatização menos consistente. Entretanto, não é possível entrever uma reação verdadeiramente diferente em relação às outras escolas, já que, para os atributos mais relevantes, como os das dimensões da competência e da aparência, há quase sempre estigmatização do guarani.

\section{FECHANDO A CORTINA: O ENSINO NO CONTEXTO MULTILINGUE}

A fronteira se caracteriza por certo grau de imposição de uma cultura dominante, que se traduz, nesse âmbito, pelo letramento em português ou em espanhol de falantes do guarani como L1, ainda que essa situação se disfarce em discursos públicos que conferem ao guarani o status de língua oficial do Paraguai ao lado do espanhol. Por trás dos discursos oficiais, flagra-se na verdade um cenário real de bilinguismo com diglossia cuja consequência é a imposição de uma língua dominante, o espanhol, tendo como implicação óbvia, também, a ativação de uma situação típica de letramento dominante. Essa relação dual se agrava ainda mais na fronteira com a interferência do português, que acaba competindo com o espanhol pelo status de língua dominante.

Nesse cenário de letramento dominante, atua um princípio amplamente aceito na sociolinguística, o de conflito entre diferentes sistemas de valores. Com efeito, um dos obstáculos que oferecem maior resistência à aquisição de uma variedade ou língua padrão, em situação mono ou multilíngue, segundo Labov (1974 [1964]), é justamente a barreira interposta por esse tipo de confronto.

Assim, se é socialmente estigmatizada uma língua, como o guarani na situação fronteiriça, em contraposição à língua de maior grau de prestígio, veiculada principalmente pelo sistema de ensino, instaura-se um conflito entre os valores que a instituição escolar pretende inculcar e os que o aprendiz compartilha com sua própria comunidade que, em última instância, identificam-no simbolicamente como membro dela.

Recusar-se a aprender a língua dominante, espanhol ou português num contexto multilíngue, pode significar, para um membro de uma comunidade socialmente marginalizada, caso dos falantes do guarani, a rejeição dos valores culturais próprios da classe dominante que se acham implícitos na expressão verbal e, ao mesmo tempo, a preservação de sua própria identidade social cujas bases se assentam no guarani, língua nativa da maioria dos alunos das escolas de fronteira.

Mutatis mutandis, pode significar igualmente o abandono da cultura guarani pela adoção simples da cultura da língua prevalecente, numa situação típica de letramento dominante. Segundo Bagno (2004), o tipo mais trágico de preconceito é justamente o que uma pessoa exerce contra si mesma, como se falar guarani num contexto de letramento dominante implicasse um status negativo em comparação com os demais cidadãos paraguaios falantes do espanhol.

Enquanto a primeira situação é um tipo de comportamento provocado por prestígio encoberto, que, como se viu, também se aplica ao guarani em certas circunstâncias sociais, a segunda situação é provocada por prestígio aberto atribuído às línguas com status superior no cenário multilíngue da fronteira.

Uma das opções viáveis para contornar a rejeição tanto da língua mais prestigiosa quando da língua estigmatizada, não a única certamente, deve ter por base uma estratégia de ensino assentada numa pedagogia culturalmente sensível, que, segundo Erickson (1987), por ser um meio adequado de transformação em um contexto de diferenças culturais entre alunos e professores, não faz distinção social entre variedades numa situação monolíngue e entre 
diferentes línguas numa situação multilíngue ${ }^{5}$.

Essa abordagem permite o estabelecimento de confiança entre os atores a partir da acomodação das práticas pedagógicas às normas culturais familiares dos aprendizes, o que é percebido pelos próprios alunos como uma afirmação simbólica. Nas palavras do autor,

Culturally responsive pedagogy is one kind of special effort by the school that can reduce miscommunication by teachers and students, foster trust, and prevent the genesis of conflict that moves rapidly beyond intercultural misunderstanding to bitter struggles of negative identity exchange between some students and their teachers. (...) It is only one more piece in a large puzzle, yet it provides a positive option for educators who wish, through critically reflective practice, to improve the chances for learning by their students and to improve their own work life as well. Culturally responsive pedagogy is not a total solution. It can, however, be seen as part of a total solution that also includes work to transform the general society within which schooling takes place (ERICKSON, 1987, p. 355).

Trata-se, portanto, de incorporar ao ensino da variedade padrão formas de registro falado e escrito dos alunos e discutir, com eles próprios, os valores atribuídos a essas práticas sociais. Para tanto, é tarefa do professor, num sistema de ensino culturalmente sensível, descobrir as práticas interacionais mais familiares aos alunos e adotá-las como ponto de partida na pedagogia da língua com a única finalidade de favorecer o desenvolvimento de aprendizagem. Afinal de contas, entende Soares (1998), o problema da pedagogia da língua não se limita a ensinar a ler e a escrever, mas se estende, sobretudo, à condução dos indivíduos - crianças e adultos - no envolvimento com práticas sociais de leitura e de escrita.

Uma pedagogia culturalmente sensível, como a que advoga Erickson (1987), permitiria, antes de tudo, separar letramento de alfabetização, ou escolaridade em geral, uma estratégia necessária em função de indícios revelados nos dados de avaliação subjetiva como casos típicos de prestígio encoberto atribuído ao guarani, a comprovar que as práticas de letramento são constitutivas da identidade e da pessoalidade (STREET, 2006).

Permitiria também incorporar habilidades argumentativas, como as discutidas por Tfouni (1994), para criar certa cumplicidade com o interlocutor, que consistem em práticas sociais da oralidade, passíveis de ser transpostas para a escrita, num cenário institucional onde a pedagogia não culturalmente sensível, que é em geral a que se exerce no sistema de ensino, é a de um letramento baseado exclusivamente em práticas sociais escritas.

É por isso que a imagem da situação de aprendizagem é o que o aluno pensa que a escola espera dele, isto é, o registro mais formal, codificado numa morfossintaxe e num léxico estranhos aos do uso quotidiano. É esse imaginário que ativa no indivíduo escrevente a prática social de parodiar a escrita formal com eruditismo desgastado e períodos redundantes, como mostra Tfouni (1994).

Num ambiente multilíngue, dominado por um sistema próprio de valores e crenças, o falante do guarani pode ser levado a abandonar sua língua veicular, tomada como inferior em proveito da língua imposta pelo letramento dominante. Uma pedagogia culturalmente sensível, no entanto, deveria ser capaz de identificar as relações políticas de dominação e isolar a situação de conflito intercultural entre as três línguas da fronteira em relação tanto ao processo de alfabetização quanto ao de letramento, dando pleno reconhecimento inclusive às situações em que se atribui ao guarani, o vértice frágil do triângulo, um valor de prestígio encoberto. Um recurso metodológico bem-vindo é a incorporação de práticas sociais faladas, como por exemplo, narrativas vivas na língua veicular, a que se associariam equivalentes de

\footnotetext{
${ }^{5}$ Bortoni-Ricardo (2003) e Pinto e Cyranka (2010) também advogam a favor de uma pedagogia culturalmente sensível mesmo em situações diglóssicas sem bilinguismo, como é o caso da diversidade linguística do português brasileiro.
} 
forma e de conteúdo em espanhol e em português, quando for o caso.

Blommaert et al. (2005) defendem que o caráter homogeneizador vinculado a práticas políticas, como a de imposição de letramento dominante, que só admite enxergar diferenças em sociedades desiguais, obscurece a visão e a avaliação acurada das dinâmicas locais, como o caso do prestígio encoberto, ocorrendo em partes desse sistema.

A margem, por assim dizer, onde se abriga o guarani, não é necessariamente um espaço onde as pessoas falham em seguir as normas. É, na realidade, um espaço onde se produzem normas diferentes, mas relacionadas entre si, em resposta às limitações do letramento dominante, uma posição que coincide com o conceito de escola culturalmente sensível postulado por Erickson (1987) e também defendido aqui.

\section{Referências}

BAGNO, M. Preconceito linguístico: o que é, como se faz. São Paulo: Edições Loyola, 2004.

BAKER, C. Attitudes and language. Adelaide, Australia: Multilingual Matters, 1992.

BLOMMAERT, J. et al. Peripheral normativity: Literacy and the production of locality in a South African township school. Linguistics and Education, [S.L]. v. 16, p. 378-403, 2005.

BORTONI-RICARDO, S. M. Processos interativos em sala de aula e a pedagogia culturalmente sensível. Polifonia. Cuiabá. V. 7, p. 119-136, 2003.

CYRANKA, L. F. de M. Atitudes linguísticas de alunos de escolas públicas de Juiz de Fora $M G .174$ f. Tese (Doutorado em Estudos Linguísticos). Instituto de Letras, Universidade Federal Fluminense, Niterói, 2007.

ERICKSON, F. Transformation and School Success. Antrophology and Education Quarterly. [S.L]. Vol. 8, n. 4, p. 335-356, 1987.

FERGUSON, Ch. H. Diglossia. Word, [S.L]. v. 15, p. 325-340, 1959.

FERRARO JÚNIOR, V. G.; BUITONI, M. M. S. A integração na fronteira seca: Ponta Porã (Brasil) e Pedro Juan Caballero (Paraguai). SEMANA DE INICIAÇÃO CIENTÍFICA DA PUC-SP, 19, 2010. Pontifícia Universidade Católica de São Paulo. Artigos premiados da $19^{a}$. Disponível

em:

$<$ http://www4.pucsp.br/iniciacaocientifica/20encontro/downloads/artigos/vicente ferraro.pdf $>, 2010$, p. 1-10. Acesso em: 25 nov 2016.

FIAMENGUI, A. H. R. Multilinguismo e preconceito na fronteira Porã: um estudo sobre atitudes e crenças linguísticas. Tese (Doutorado). Programa de Pós-Graduação em Estudos Linguísticos. Universidade Estadual Paulista, Instituto de Biociências, Letras e Ciências Exatas, São José do Rio Preto, 2017.

FISHMAN, J. A. Bilingualism with and without diglossia; diglossia with and without bilingualism. Journal of Social Issues, [S.L]. v. 23, n. 2, p. 29-38, 1967.

FISHMAN, J. A. "Nationality-Nationalism and Nation-Nationism". In: FISHMAN, J. A.; FERGUSON, C. A.; GUPTA, J. Das (Ed.). Language Problems of Developing Nations. New York: John Wiley and Sons, p. 39-51, 1968. 
GAONA VELÁZQUEZ, I. A. El bilingüismo guaraní castellano y su incidencia en la producción escrita de los alumnos al final del primer ciclo de la EEB. Trabalho final de pósgraduação. Universidad Nacional de La Plata. Facultad de Humanidades y Ciencias de la Educación. En Memoria Académica, 2013.

GRILLO, R. Dominant languages. Cambridge: Cambridge University Press, 1989.

GUMPERZ, J. J. "Types of linguistic communities". In: FISHMAN, J. (ED.) Readings in the sociology of language. The Hague: Mouton, p. 460-72, 1968.

GYNAN, S. N. "Language Planning and Policy in Paraguay:an update". In: BALDAUF JUNIOR, R.B.; KAPLAN, R. B. (ed.). Latin America, vol. 1: Ecuador, Mexico and Paraguay. Ontario: Multilingual Matters, p. 284-301, 2007.

JIMÉNEZ, D. A. El bilinguismo paraguayo por dentro: influencias de la lengua española sobre el guaraní hablado en Paraguay. Asunción, Paraguay: Servilivro, 2011.

LABOV, W. "Estágios na aquisição do inglês standard". In: FONSECA, M.; NEVES, M. (Org.). Sociolinguística. Rio de Janeiro: Eldorado, p. 49-86, 1974 [1964].

LABOV, W. Padrões sociolinguísticos. Trad. Marcos Bagno, Maria Marta Pereira Scherre e Caroline Rodrigues Cardoso. São Paulo: Parábola Editorial, 2008 [1972].

LAMBERT, W. et al. Evaluation reactions to spoken languages. Journal of Abnormal Social Psychology, [S.L]. n. 60, p. 44-51, 1960.

LIKERT, R. A technique for the measurement of attitudes. Archives of Psychology. [S.L]. n. 140, p. 44-53, 1932.

MACNAMARA, J. The bilingual's linguistic performance: a phychological over view.Journal of Social Issues, [S.L]. v. 23, n. 2, 58-77, 2010.

PINTO, C. D. M.; CYRANKA, L. F. de M. Aportes sociolinguísticos à prática do professor implicações na sala de aula. Cadernos de CNLF, [S.L]. Vol. XIV, n. 2, p. 501-513, 2010.

SEBRAE NACIONAL. Mato Grosso do Sul sem fronteiras: características e interações territoriais. Bolívia. Brasil. Paraguai. 1.ed. Campo Grande/MS: Editora Visão, 2010.

SILVA, G. M. da; TRISTONI, R. H. P. Diversidade cultural e linguística nas escolas de fronteira Brasil/Paraguai. Revista Travessias. Florianópolis. Ed. XIV, 2010.

SOARES, M. B.. Letramento: um tema em três gêneros. Belo Horizonte: Autêntica, 1998.

SOARES, M. B. Letramento e alfabetização: as muitas facetas. Revista Brasileira de Educação, [S.L]. v. 25, p. 5-17, 2004.

SPINASSÉ, K. P. Os conceitos Língua Materna, Segunda Língua e Língua Estrangeira e os falantes de línguas alóctones minoritárias no Sul do Brasil. Revista Contingentia, [S.L]. v. 1, p. 1-10, 2006. 
STREET, B. Perspectivas interculturais sobre o letramento. Filologia e Lingüistica Portuguesa, [S.L]. v. 8, p. 465-488, 2006.

TFOUNI, L.V. Perspectivas históricas e a-históricas do letramento. Cadernos de Estudos Linguísticos, [S.L]. v. 26, p. 49-62, 1994.

TRUDGILL, P. Sex, covert prestige and linguistic change in the urban British English of Norwich. Language in Society, [S.L]. v. 1, n. 2, p. 179-195, 1972.

WÖLCK, W. "Attitudes toward Spanish and Quechua in bilingual Peru". In: SHUY, R.W.; FASOLD, R.W. (ed.). Language Attitudes: Current Trends and Prospects. Washington: Georgetown University Press, p. 129-147, 1973.

ZARRATEA, T. Aspectos del bilinguismo paraguayo. Barcelona: 30 ${ }^{\mathrm{a}}$ Liber, Feria Internacional del Libro, outubro de 2012. Palestra na Feira Internacional do Livro de Barcelona, Espanha. Disponível em: $<$ http://mbatovi.blogspot.com.br/2012/10/aspectos-delbilinguismo-paraguayo.html>. Acesso em: $19 \mathrm{dez} 2016$.

Roberto Gomes Camacho roberto.camacho@unesp.br

Ana Helena Rufo Fiamengui anahelena@ifsp.edu.br

Recebido em: 08 de Julho de 2019 Aceito em: 18 de Agosto de 2019 Publicado em: Setembro de 2019 